\title{
Remedios para un cuerpo político que declina. El arbitrismo de Manuel Gaytán de Torres y el estrechamiento de los vínculos transatlánticos de la monarquía hispánica (siglo XVII)/
}

\author{
Remedies for a Body Politic in Decline. Manuel Gaytán \\ de Torres' Arbitrism and the Strengthening of Transatlantic \\ Ties in the Spanish Monarchy (17th century)
}

Arrigo Amadori

Universidad Complutense de Madrid

Este artículo analiza los memoriales del jerezano Manuel Gaytán de Torres, quien elaboró un arbitrismo de gran envergadura, heterogeneidad y originalidad de síntesis que articula problemáticas y espacios geográficos diversos en una propuesta funcional del mundo ibérico. Su obra permite contemplar la construcción intelectual de la monarquía policéntrica desde la óptica de un arbitrismo en el que los virreinatos americanos se relacionan de forma sistémica con el mundo europeo, reproduciendo las percepciones contemporáneas acerca de las dificultades y de las soluciones para los disfuncionamientos de las posesiones de los Austrias.

Palabras Clave: Manuel Gaytán de Torres; Cultura política; Arbitrismo; Reforma; Restauración; Monarquía policéntrica; América; Siglo XVII.

This article analyses the memorials of Manuel Gaytán de Torres, a native of Jerez who developed an arbitrism of great scope, heterogeneity and originality of synthesis that articulates various issues and geographic spaces into a functional proposition of the Iberian world. His work facilitates an understanding of the intellectual construction of the polycentric monarchy from the perspective of an arbitrism in which the American viceroyalties are systematically related to the European world, and reproduces contemporary perceptions of the difficulties posed by the different dysfunctions of the Austrian possessions and their solutions.

KEYwords: Manuel Gaytán de Torres; Political culture; Arbitrism; Reform; Restoration; Polycentric monarchy; America; 17th century. 


\section{Planteamiento}

Puede aceptarse que una de las perspectivas de análisis más fructíferas de los últimos tiempos en el ámbito de la historia moderna ha sido la consideración del mundo hispánico como un espacio densamente interconectado por vínculos de diversa naturaleza. Luego de mucho tiempo en el que el desenvolvimiento de los múltiples componentes de este organismo se abordara preponderantemente de forma autónoma, sobre todo en lo que respecta al mundo europeo y al americano, o siguiendo un rígido esquema de centro-periferia, actualmente se enfatiza su carácter sistémico y los planteamientos se han vuelto más sensibles a fenómenos relevantes como la circulación o la presencia a gran escala de ideas, discursos, agentes, redes interpersonales, vínculos familiares, prácticas políticas, dinámicas sociales, referentes identitarios, etc. De modo que se ha producido la construcción de un espacio mucho más denso y de mayor amplitud que el generado por opciones sugeridas muchas veces por realidades políticas contemporáneas o por especialidades académicas, lo que a su vez ha dado lugar a lecturas complejas, dinámicas e integradas de una multitud de fenómenos más allá de los nexos mercantiles, las remesas de metales o las relaciones políticas, áreas que tradicionalmente han suscitado el interés primordial en el estudio de los nexos transatlánticos. Se han subrayado, por tanto, los múltiples elementos o mecanismos de cohesión propios del mundo ibérico, enfatizando el papel de la monarquía como espacio político, como ámbito económico o, incluso, como área cultural donde el diálogo entre sus componentes, propiciado entre otras cosas por la movilidad de los agentes reales y por la circulación de discursos políticos, ha ido ganando terreno bien de manera explícita o bien de forma implícita como clave de interpretación del funcionamiento de las monarquías planetarias de inicios de la edad moderna. No conviene soslayar el hecho de que esta visión policéntrica, por utilizar una de las últimas denominaciones propuestas, recobra la perspectiva y las experiencias de los contemporáneos, implicados directamente en la construcción y el funcionamiento del extenso mundo hispánico durante el siglo XVII. ${ }^{1}$

Precisamente esta es la clave del análisis que se adopta en este trabajo, que estudia el fenómeno del arbitrismo de naturaleza transatlántica a partir de la obra del memorialista jerezano Manuel Gaytán de

1 Cardim, et al., 2012. 
Torres. ${ }^{2}$ Este autor elaboró un arbitrismo de gran envergadura, heterogeneidad y, sobre todo, originalidad de síntesis, que fue capaz de articular problemáticas y espacios geográficos diversos en una propuesta funcional del mundo ibérico. De hecho, su programa de reformas, que incorpora varias ideas y nociones de los debates sobre la restauración de la monarquía que tuvieron lugar a partir de los años finales del reinado de Felipe III, conjugadas con los planes de otros memorialistas de temática local y con propuestas propias, fruto de su experiencia en el Nuevo Mundo, definió un extenso espacio transatlántico en el que Castilla y los virreinatos americanos integran una unidad firmemente articulada según una lógica sistémica de carácter mercantilista. Asimismo, si bien sus memoriales recogían algunas de las principales preocupaciones del régimen del conde-duque de Olivares, presentes en el ambiente de ideas y de profundo debate de la década de 1620 , lo cierto es que su reformismo proponía un proyecto de integración y fomento a largo plazo a ambos lados del Atlántico que incrementara la riqueza del reino por medio de la agricultura, la industria, la preservación de los metales preciosos y el aumento de los tratos y permitiera, al mismo tiempo, el saneamiento de la Real Hacienda y la simplificación del sistema contributivo. En definitiva, como se intentará poner de manifiesto, su propuesta está impregnada de una nueva convicción en la capacidad transformadora de la actividad política, en este caso ejecutada por el monarca y su valido, a quienes atribuye un papel decisivo en el regeneracionismo de la monarquía mediante el establecimiento de un marco propicio para una relación más armónica y equilibrada entre rey y reino. Un vínculo, en suma, afirmado en la reciprocidad y la colaboración que revirtiese la situación que en términos fiscales y contributivos se estaba experimentando sobre todo en Castilla. ${ }^{3}$ De este modo, Gaytán esboza un nuevo modelo de relación, demandada fuertemente por el arbitrismo de finales de la década de 1610, en el que el incremento de la riqueza del reino, la articulación y la complementariedad entre sus distintos miembros, y la disminución de las cargas fiscales extraordinarias fueran el motor de la recuperación de los ingresos y del poder real.

2 Puede consultarse una propuesta acerca de la importancia del arbitrismo dentro del contexto político de principios del siglo XVII y del tratamiento que ha recibido el fenómeno en su vertiente americana en la introducción a este dossier.

3 Sobre este tema pueden consultarse las obras de Gelabert, 1991 y 2001. 


\section{Un arbitrista de dos mundos}

Probablemente, uno de los elementos que más destaque de la obra de Manuel Gaytán de Torres sea el hecho de que tanto su reflexión como sus propuestas reformistas parten de una visión sistémica del mundo hispánico, que se traduce tanto en la heterogeneidad de problemáticas y soluciones complementarias que llaman su atención, como también en el marco espacial considerado por sus escritos. En concreto, la singularidad de su arbitrismo no se explica si no se parte de una circunstancia fundamental de su trayectoria vital: su doble experiencia, andaluza y americana.

Nuestro personaje nació en 1577 en Jerez de la Frontera, donde falleció en 1633. Pertenecía a uno de los principales linajes locales y estaba emparentado con las familias más ilustres del lugar. ${ }^{4}$ En concreto, poseía un vínculo fundado por sus padres y era titular de una veinticuatría, lo que le permitió adquirir una importante experiencia en el gobierno municipal y un conocimiento más acabado de las necesidades locales y de las dinámicas institucionales de la monarquía. Si bien son pocos los datos certeros que tenemos sobre su vida hasta el año 1619, en esta fecha lo encontramos en la corte de Madrid procurando interesar a los consejeros de Indias en un proyecto destinado a la instalación de ingenios y fundiciones de cobre en la península, y gestionando una visita a las recién descubiertas minas de Cocorote, en la provincia de Venezuela. ${ }^{5}$ Probablemente esta visita haya resultado de suma importancia para su comprensión de los problemas de la monarquía, ya que le habría permitido entrar en contacto con el intenso movimiento regeneracionista cristalizado en la formación de la Junta de la Reformación, establecida precisamente este mismo año. ${ }^{6}$ En 1620 se le encargó la visita a dichas minas venezolanas con la doble finalidad de com-

4 Para más datos biográficos de los que aquí se aportan puede consultarse la información que Joseph Manuel de Ayala obtuvo de un descendiente de Manuel Gaytán de Torres, don Francisco Ponce de León y Torres, inserta, en cinco folios sin numerar, a comienzos de los Discursos (Gaytán, 1625b). Véase también: Real Academia de la Historia, Colección Salazar y Castro, 25, tabla genealógica de la familia Gaytán, 122; Spínola y Torres, 1916 [1630], 26-27 y Amadori, 2009, 153-155.

5 Urbani, 1992, 159. Archivo General de Indias (AGI), México, 2, 258, Consulta del Consejo de Indias sobre las informaciones que don M. Gaytán de Torres ha dado sobre las minas de las provincias de Santa Marta y Venezuela, Madrid, 16 de septiembre de 1622. Las minas cobre de Cocorote o Aroa fueron descubiertas en 1612 por don Alonso Sánchez de Oviedo. Hacia mediados de esta década el Consejo de Indias se interesó por las minas y la Casa de la Contratación realizó unos estudios con muestras de metal y piedra enviadas por el gobernador de Barquisimeto García Girón. Sobre estas minas: Verna, 1988, 191-192.

6 González Palencia, 1932. 
probar la calidad del metal de los yacimientos y su productividad potencial, y estudiar el entorno para evaluar si el asentamiento era propicio para la infraestructura de explotación y beneficio. ${ }^{7}$ La comisión tuvo una ejecución bastante rápida, puesto que en junio de 1621 Gaytán ya había redactado y mandado a imprimir una relación sobre las minas de Cocorote. ${ }^{8}$ Luego de su regreso a Madrid, que debe situarse a finales del mismo año, fue enviado a Sevilla para que, con asistencia del factor de la Casa de la Contratación, hiciera algunos experimentos con las muestras del metal venezolano. Más tarde, el Consejo de Indias encargó el seguimiento del asunto de las minas de Cocorote a Rodrigo de Agüiar y Acuña, quien debía tratar con Gaytán cada uno de los puntos del informe y evaluar sus conveniencias y dificultades. Si bien don Manuel fue reputado como una persona «bien entendida, de buena intención e inteligencia», dado que el asunto revestía gran importancia, requería pericia técnica y suponía un gasto muy significativo para la Real Hacienda, el Consejo sugirió adoptar una postura cautelosa y solicitar la intervención del gobernador y de algunas personas principales de la gobernación de Venezuela para que volvieran a considerar el proyecto y ofrecieran su parecer por escrito. En última instancia, planteaba la consulta, una vez que se hubiera considerado cautelosamente con la concurrencia de toda esa gente y se decidiera poner el plan en ejecución, don Manuel podría ser enviado para acometerlo. ${ }^{9}$ Sin embargo, ni el plan de Gaytán fue puesto en práctica ni sus servicios volvieron a ser solicitados para dicho asunto, aunque su participación en la administración local, su experiencia directa del mundo colonial, y su conocimiento de las dinámicas cortesanas le permitieron proponer un arbitrismo muy singular.

En la obra de Gaytán, la monarquía como posesión patrimonial se presenta como el sujeto de un diagnóstico galénico y como acreedora genérica a un tratamiento que debía no solo evitar su pérdida sino también procurar su restauración. En esta línea, reproduciendo buena parte del repertorio conceptual del arbitrismo para describir la finalidad de sus memoriales, expresaba que

7 Urbani, 1992, 159.

8 Los únicos ejemplares que conozco se conservan en la British Library, C.62.i.19.(49.) y 725.k.18.(41.). Existe una edición facsimilar de Moreno Garrido, 1968 — que es la que utilizo—y una transcripción en Urbani, 1992.

9 AGI, México, 2, 258, Consulta del Consejo de Indias sobre las informaciones que don M. Gaytán de Torres ha dado sobre las minas de las provincias de Santa Marta y Venezuela, Madrid, 16 de septiembre de 1622 . 
el alma, señor Excelentísimo, de este sujeto es representar las causas y principios de los daños que esta monarquía está padeciendo así de mar como de tierra, señalando prácticamente medios certísimos para su reparo, juzgo con evidencia clara, que si V. Ex. les da audiencia que ha de mandar se ejecuten puntualísimamente y ha de gozar España por mano de VE el mayor beneficio que puede esperar como es su total desempeño sin cargo de imposiciones, pechos y gabelas. ${ }^{10}$

Sus escritos, producto de la percepción de decadencia que se generó en Castilla desde principios del siglo XVII, ${ }^{11}$ perseguían el «reparo» del cuerpo político, tanto por medio de la restauración del orden y las virtudes que habían hecho posible las antiguas glorias, como a través de la introducción de reformas de gran envergadura que aprovecharan su potencial y lo pusieran en sintonía con los cambios introducidos por el paso del tiempo y la variación de la coyuntura exterior. La centralidad que en el discurso de Gaytán posee la restauración se deduce de la creencia en la necesidad de revitalizar al cuerpo político mediante el fortalecimiento del poder real y de sus mecanismos anejos, la Real Hacienda y el servicio militar, como condición esencial de la conservación de la monarquía. En este sentido, la atención que sus memoriales conceden a la eficacia del príncipe y a la exaltación del servicio obediente de los súbditos parece revelar la irrupción de la razón de estado, una auténtica doctrina de la conservación de la república, que se convirtió en la fuente última de legitimidad de la acción del monarca. ${ }^{12}$ Sin embargo, no debe perderse de vista que Gaytán también reserva una porción esencial de la responsabilidad a la acción de los súbditos, aunque claramente guiada y propiciada por el poder real.

Según se esfuerza en señalar, los remedios propuestos para «alcanzarle salud» al cuerpo político convenían indistintamente a sus dos componentes estructurales, rey y reino, aunque es cierto que Castilla y los virreinatos americanos acaparan su atención. Uno de los puntos de anclaje de sus proyectos reformistas es la constatación de que el vínculo transatlántico estaba experimentando severos problemas en sus elementos centrales: el gobierno y la administración indiana, el comercio transatlántico, la fiscalidad y la defensa de los virreinatos, que naturalmente guardaban una estrecha relación entre sí. De este modo, Gaitán se hace eco de la paulatina pér-

10 Gaytán, 1625a, 2.

11 Sobre la percepción de decadencia, véase Elliott, 1983.

12 Gil Pujol, 2000, 359. Respecto de la razón de estado en Castilla es fundamental la obra de Fernández-Santamaría, 1986. Sigue siendo útil la compilación de artículos de Maravall, 1986. Un análisis de referencia del cambio en el sentido de la política en Viroli, 2009. 
dida de sincronización entre las exigencias de la política dinástica, las tendencias de las posesiones americanas y la coyuntura de la economía castellana, fenómeno que desde la década de 1610 comenzó a ser contemplado con preocupación en la corte de Madrid. ${ }^{13}$ Sus memoriales apuntan a revivificar esos canales, pero nuestro autor, aunque en ocasiones señala las causas que habían provocado los cambios y el referido alejamiento, prioriza claramente la dimensión política del problema que es donde también sitúa la solución.

Ahora bien, frente a una lectura pesimista acerca del influjo del mundo colonial en el complejo hispánico y especialmente en Castilla que comenzó a desarrollarse en Castilla durante las primeras décadas del siglo XVII,$^{14}$ Gaytán estaba plenamente convencido de que las Indias seguían siendo uno de los baluartes de la monarquía, sin el cual no cabía posibilidad alguna de revertir la situación de la Real Hacienda. Para él, en caso de seguir descendiendo las remesas americanas, se habrían de «llevar tras de sí lo que resta de esta Monarquía porque si le falta el dinero que cada año viene porque no tiene otra sustancia, renta ni hacienda sino la que viene de las Indias y si no se mira por ellas cierta será su ruina y estos reinos estar sin sustancia para poder socorrer a su Majestad». ${ }^{15}$

\section{Un espejo de virtud: la reforma de la administración}

De la variedad y diversidad de temáticas abordadas en la obra de Gaytán, el problema de la administración atrae su atención y constituye un elemento esencial de toda su propuesta reformista. Según afirmaba en las Reglas, el celo regeneracionista del príncipe debía concentrarse en el gobierno de la monarquía, «por ser como es [responsable del] bien o el mal de los Reynos y Repúblicas», y sus integrantes «cabezas y espejos de los demás» que irradiaban su influencia sobre el conjunto de los sectores sociales. ${ }^{16} \mathrm{De}$ este modo, entendía a la monarquía como un ente moral, en el que existía un relación muy estrecha entre las cualidades del gobierno y la suerte del conjunto de la sociedad, que obligaba a que, tanto la organización de la administración como los individuos que ejercían las funciones públicas

13 Amadori, 2013, 459 y ss.

14 Elliott, 1971.

15 Gaytán, 1625a, 65-66.

16 Ibidem, 66 y 7 respectivamente. 
fueran idóneos y se guiaran según los altos ideales que debían irradiar al cuerpo político. ${ }^{17}$

El énfasis puesto por Gaytán en la solución de los problemas de la administración respondía no solo a una lectura corporal del entramado sociopolítico, sino que también se adscribía dentro de los importantes cambios en la percepción y en las expectativas que se tenían en la capacidad de la actividad política y el gobierno. Como ha planteado António Manuel Hespanha hace ya algún tiempo, durante los años que nos ocupan se buscó perfilar un poder político que sobrepasara la «defensa del orden socio-jurídico establecido y se mostrara, progresivamente, como una administración activa, creadora de situaciones políticas nuevas». ${ }^{18}$ Parte de la élite política de la monarquía — entre la que debemos ubicar a Olivares y su facciónasí como también una porción del movimiento arbitrista, daba por supuesta la capacidad del poder político para introducir cambios en el entorno físico, económico e incluso social, de ahí que le asignaran a la administración el papel principal en la movilización de los recursos de la monarquía, en la subsanación de los desajustes y, en definitiva, en la restauración de la vitalidad y el poderío perdidos..$^{19}$ En esta línea, según ha señalado Elliott, para el valido y para buena porción de los arbitristas la restauración del reino era una cuestión de gestión política más que de dinámica social, con lo cual parece tener lugar un intento deliberado de superar el carácter estrictamente jurisdiccional del poder del monarca que se limitaba a preservar la armonía entre las corporaciones de sus reinos. ${ }^{20}$

Partiendo de esta forma de entender la función, la incidencia y las expectativas del gobierno, Gaytán centró su diagnóstico en la pérdida de vigor del ideal de servicio al monarca que se estaba experimentando entre los individuos que tenían a su cargo la administración. ${ }^{21}$ El mal gobierno que imperaba, amenazando con la pérdida de la monarquía, era el resulta-

17 Un indicador interesante de esta inclinación es la cantidad de veces que Gaytán vincula la necesidad de introducir reformas en el cuerpo político con la conciencia real.

18 Hespanha, 1989, 217. El resaltado es del original.

19 Elliott, 2004, 117. Para este mismo autor, «tanto los escritos de los tratadistas económicos como el ejemplo de las naciones extranjeras comenzaban a crear un clima en el cual se daba por supuesto la capacidad del hombre para alterar su ambiente físico y económico. Por consiguiente, más se esperaba del gobierno en el siglo diecisiete de lo que se había esperado en el dieciséis». Elliott, 1977, 151.

20 Elliott, 2004, 216. Sobre el carácter jurisdiccional de la monarquía moderna véase, entre otros, Clavero, 1996.

21 En su memorial de 1625 Gaytán cita tan solo a Castillo de Bobadilla, (1597) y a Santa María, (1619). La interpretación de este último del problema y de las soluciones correspondientes a la administración poseen un gran influjo en su obra. 
do del deservicio al rey provocado por el relegamiento de los intereses reales y de la política dinástica en favor del provecho individual. Lamentaba Gaytán que

Su Majestad y Padre, que está en el cielo, han sido reyes desgraciados con ministros que teniendo tantos y tan gratificados con tantas mercedes de hábitos, rentas y mejoras de oficio como les han dado no conozco cual haya sido el que se haya dolido de Su Majestad ni del estado de esta monarquía ni bien común de ella, porque está introducido poner en primer lugar cada uno sus aprovechamientos que al servicio de $\mathrm{Su}$ Majestad: y esta verdad conocerá V. Ex. volviendo los ojos a tantas pérdidas como ha habido en estos tiempos y el empeño en que está Su Majestad y tantos mayorazgos como se han hecho, tantas cosas como han labrado que ve V. Ex. cada día que sale por Madrid y que, al paso que esto crece, disminuye la hacienda de Su Majestad y el común de estos reinos. ${ }^{22}$

Para Gaytán, la búsqueda del interés particular había alterado la naturaleza de la administración, perjudicando a la Real Hacienda y bloqueando cualquier intento de introducir reformas. En esta línea, aseveraba que los servidores desleales, «que con malos medios adquirieron los oficios en que están», «se llevan lo mejor de las Indias y son el fuego de ellas y han de dar ocasión a que todas se levanten». ${ }^{23}$ Esta búsqueda del beneficio por medio de la administración, corruptora del cuerpo político, constituía la antítesis de lo que debía ser el servicio al monarca. Para nuestro autor, lejos de ser una ocasión para lucrarse, creencia que parecía haberse instalado en la administración, el ejercicio de un oficio podía tener unas consecuencias muy graves que solo convenía afrontar por la obligación de servir al rey. De hecho, aseveraba que los «hombres ajustadísimos en su conciencia [...] reconocían el riesgo que corre un alma en el gobierno», de modo que aquel que pretende un oficio «muy lejos está de reconocer este riesgo y carga que se hecha sobre sus hombros, [sino que] mira solo los resplandores del oro de la corona más no la carga y peso incomportable de quien se ciñe las sienes con ella». ${ }^{24}$ Por lo tanto, la codicia presente en el gran mercado de oficios de la corte de Madrid relegaba el orden virtuoso, consistente en el nombramiento de aquellos que no acudían a procurarse un cargo sino a quienes los evitaban. Estos últimos individuos solían resultar realmente buenos para el gobierno. ${ }^{25}$

22 Gaytán, 1625a, 30.

23 Ibidem, 23.

24 Ibidem, 8-9.

25 Véase infra a partir de la nota n. ${ }^{\circ} 28$. 
Ahora bien, si la disfuncionalidad se constataba en prácticamente todos los niveles de la administración colonial, lo cierto es que Gaytán se ensañó con la que consideraba la hidra de todos los males: el Consejo de Indias, donde aún se dejaba sentir la influencia del duque de Lerma. Pese a que sus Discursos fueron publicados en 1625, el arbitrista había desempeñado una gestión cortesana hacia finales del reinado de Felipe III, conociendo de primera mano la situación del sínodo. Reproduciendo las acusaciones con las que los agentes de Olivares procuraron impugnar al anterior valido durante los primeros años de su privanza, acusaba a Lerma y a su facción de haber copado el Consejo de Indias con el objetivo de beneficiarse del patronazgo indiano, ya fuera con la promoción de sus criados como con la negociación de los oficios. El resultado había sido un «depravado estilo de gobierno» que, entre otras cosas, había servido para «favorecer a los deudos, amigos y bienhechores que tienen en las indias» y obtener ganancias ilícitas.$^{26}$ Precisamente por estos motivos el sínodo había boicoteado la adopción de algunas reformas necesarias en las instituciones americanas y la supresión de oficios transatlánticos. En consecuencia, ya en la introducción de sus Discursos Gaytán resaltaba la necesidad de no tramitar su escrito de forma ordinaria, es decir, por medio del sínodo, sino en una junta particular con consejeros de confianza, puesto que «las más de las [materias] que advierto en este discurso tratan de cercenar aprovechamientos de ministros». ${ }^{27}$ Asimismo, cuestionaba al Consejo por su incapacidad de adaptarse a los cambios. Como aseguraba,

la materia de gobierno más acertada es disponer las cosas que van sucediendo conforme al tiempo va mostrando y piden las ocasiones [...] y si el Consejo de Indias lo hubiera propuesto así no hubiera que condenar ni advertir en estos discursos el modo de su gobierno [...] pues en lo que había de tener firmeza ha mudado y en lo que se debe mudar de las cosas que asentaron en los principios de descubrimientos de las Indias no se ha hecho novedad como si fuesen todos los tiempos uno. ${ }^{28}$

A partir de su diagnóstico, la obra de Gaytán procuraba dar forma a una administración eficiente que asegurara el control sobre los virreinatos americanos y garantizara un elevado flujo de remesas a la península. De hecho, prácticamente no aludía a la reforma de la administración castellana. El principal baluarte de su reforma apuntaba a restaurar el ideal de ser-

26 Gaytán, 1625a, 29, 76-87.

27 Ibidem, 3.

28 Ibidem, 40. 
vicio y la calidad moral de los individuos designados para gobernar la monarquía, retomando de este modo una creencia esencial de la administración moderna según la cual los príncipes se apoyaban en sus vasallos y no en las instituciones..$^{29}$ Era preciso, por tanto, seleccionar servidores adornados de un conjunto de virtudes morales, prácticas e intelectuales, para lo cual se necesitaba cambiar la organización del sistema de patronazgo centrado en los consejos. Según Gaytán, «lo que principalmente se debe mirar en un ministro es el ajustamiento de su conciencia, que no hará advertidamente acción contra ella por cuanto tiene el mundo», y que además fuera perito en el asunto del que se encargase su oficio. De ahí que criticara duramente las hechuras de la facción de Lerma y la venalidad de los oficios. ${ }^{30}$ En su lugar, proponía un sistema que permitiera identificar a este tipo de individuos, desnudase la teatralidad cortesana aneja a la pretensión de cargos, y apreciase la capacidad personal en lugar de los servicios aludidos por los pretendientes. Asimismo, convenía evitar que la corte se llenase de pretensores que procuraban «hacer capaz su persona con servicios», ${ }^{31}$ ya que sus estancias en Madrid resultaban una carga para el reino. En su lugar, se debía prestar atención en designar a aquellos individuos de talento y virtudes, aunque se encontrasen lejos de Madrid y no hubieran dedicado su esfuerzo a conseguir un oficio con el que obtener una ganancia. ${ }^{32} \mathrm{El} \mathrm{meca-}$ nismo consistía en la erradicación de las consultas del Consejo de Indias y del patronazgo de los virreyes, a cambio de la conformación de libros en los que se consignaran las personas «que más lucen en virtud de prudencia y gobierno de sus casas y repúblicas» en cada una de las ciudades de los reinos de la monarquía. Dichos libros tenían que elaborarse por individuos de crédito que remitiesen informaciones precisas y de forma secreta de las personas idóneas de todos los rincones del mundo hispánico. Estas relaciones permitirían al monarca y a sus asesores la rápida consulta de candidatos apropiados para cada oficio que debía proveerse. Estimaba Gaytán que ese método resultaría muy efectivo para que se pudieran tomar decisiones con un conocimiento más preciso de los individuos y elegir «personas

29 Abellán, 1981, 106

30 Gaytán, 1625a, 11.

31 Ibidem, 20.

32 Ibidem, 7, 8, 20, 22. La idea de designar a aquellos que no pretendían los oficios ya estaba presente en La República de Platón y durante los años que nos ocupan adquirió un gran peso como testimonio de la crisis de la administración. El propio Olivares reconocía que era «necesario buscar los hombres para hallar hombres; que los que se van ofrecer o no lo son o son los más ruines». Marañón, 2006, 205. 
capaces, consultadas sin pasión ni aflicción ni particular interés». Incluso, con bastante ingenuidad, llegaba a concebir este método como un mecanismo de control, ya que la promoción de personas de vida ejemplar y virtuosa fomentaría la emulación de servir en el conjunto de la sociedad. ${ }^{33}$

En la línea de una de las preocupaciones del momento, era preciso estrechar el caudal de las mercedes que tanto había corrido durante el valimiento de Lerma y reservar las rentas para casos muy particulares. Su concesión solo debía hacerse como contrapartida de servicios militares, pero exclusivamente en beneficio de huérfanos y viudas de muertos en acto de servicio, y no en oficios de justicia, gobierno o pluma. Para estos casos, aseguraba, bastaba «por premio la grandeza que tuvieron durante el oficio». Esta proposición estaba vinculada con las ideas de Olivares acerca de los destinatarios adecuados de las honras y las mercedes, que proponían una clara inclinación a potenciar el ejercicio militar y, por tanto, la gratificación en este ámbito del servicio. ${ }^{34}$

En términos específicos, su propuesta de reformar la administración era radical, ya que siguiendo un planteamiento de máximos buscaba simplificar el complejo polisinodial mediante su reducción a solo dos organismos: estado y justicia. La pervivencia de estos sínodos, apoyados por un contador mayor y un escribano de rentas para la administración de hacienda, solucionaría el delicado problema de las disputas de jurisdicción entre los distintos consejos de la corte. ${ }^{35}$ Sin embargo, para el caso de que su propuesta fuese desechada, Gaytán sugería que se preservase el Consejo de Indias, pero poniendo especial cuidado en que sus ministros tuvieran experiencia en asuntos de gobierno, guerra y justicia, preferentemente en el ámbito americano. Además, el sínodo debía trasladarse a Sevilla, para asistir directamente al despacho de las flotas, suprimiéndose así la Casa de la Contratación.

Pero también su propuesta se extendía a los organismos americanos. Aquí Gaytán sugería distintas modificaciones, algunas de ellas de cierta envergadura, que afectaban sensiblemente al entramado institucional. En este contexto, las situaciones que consideraba de mayor gravedad eran la de la Real Hacienda y la los oficiales reales, puesto que «no solo interesa a S.M. los sueldos que da a las personas que en los tales oficios ocupa, sino

33 Gaytán, 1625a, 22.

34 Amadori, 2013, 178 y ss.

35 Gaytán, 1625a, 19 y ss. El problema de las disputas jurisdiccionales resultó tan complejo que fue necesario establecer una Junta de Competencias en 1625. 
otros daños mayores que causan las personas a cuyo cargo están los oficios que conviene cercenar». Su idea consistía en suprimir los Tribunales de Cuentas que se habían mostrado sumamente ineficaces, y establecer un sistema de control excesivamente simplificado de residencias tomadas periódicamente, evitando así el retraso en el fenecimiento de las cuentas y un ahorro de veintiséis mil ducados anuales. Siguiendo esta misma línea, buscaba terminar con los abusos cometidos por los oficiales reales perpetuos, estableciendo un sistema de nombramiento por parte de los cabildos seculares. Estos debían designar a dos regidores que durante dos años se desempeñasen como tesorero y contador, colaborando en la administración de la hacienda junto con el gobernador, en cuya residencia se inspeccionarían las cuentas de todos los cabildantes que hubiesen ejercido esta obligación. ${ }^{36}$

Si las proposiciones de Gaytán respecto de la hacienda tenían un carácter general y radical, sus ideas concernientes a la justicia resultan puntuales y localizadas. Más preocupado por aligerar a las sobrecargadas cajas americanas y maximizar los beneficios americanos, sus escritos se ciñen tan solo a una reorganización de los tribunales superiores. Apoyándose en una serie de generalizaciones y en un conocimiento poco preciso del conjunto de la América española, proponía que en todas las Indias no se mantuvieran más de tres audiencias: Lima, México y Cartagena, ya que fuera de ellas prácticamente no había razón que justificase su presencia. Basándose en un argumento semejante, también consideraba pertinente la revisión de las jurisdicciones de algunas gobernaciones por resultar muchas de ellas poco pertinentes a la evolución que habían tenido los virreinatos. Así, las gobernaciones de Trinidad, Guayana y Cumaná debían agregarse a la de Margarita, y las de Santa Marta y Cartagena tenían que agruparse en una sola, lo mismo que las de Cuba y Florida, cuya fusión favorecería la defensa del territorio y un ahorro significativo.

Finalmente, Gaytán ofrecía una medida de excepción para acabar con el gran desorden en materia de sueldos y oficios en las Indias, donde los

salarios que Su Majestad da a los ministros y otros gastos que se hacen sin ser necesarios, consumen lo más y mejor de la Real Hacienda y el sueldo y situación que una vez se pone en Caja Real nunca se quita aunque cese la causa para que se pone y así están destruidas las Cajas Reales y menoscabada la Hacienda Real y los naturales que tan encargados son de Su Majestad de que procede no venir a Su Majestad el tesoro que vendrá si a esto se pone remedio.

36 Ibidem, 79-87. 
Coincidiendo con una de las medidas reformistas desplegada por el régimen de Olivares, proponía la realización de una visita general a las jurisdicciones indianas que prometía acabar con todos los abusos que sangraban la Real Hacienda y ahorrar casi un millón de ducados en gastos innecesarios. ${ }^{37}$

\section{La Carrera de Indias: la defensa y el desenvolvimiento de una fuente de riqueza}

\section{La mudanza del comercio colonial a Cádiz y el navillo del río Guadalete}

Lejos de agotarse en el tópico del servicio al rey tan manido por el arbitrismo, las lecturas y los planes de carácter mercantil de los memoriales de Gaitán poseen el atractivo de brindar una visión que recoge las aspiraciones no solo del comercio colonial monopolista, sino también $-\mathrm{y}$ especialmente - de la ciudad de Jerez de la Frontera, que desde finales del siglo XVI atravesaba una fase recesiva en su economía al igual que otros enclaves de la Baja Andalucía. ${ }^{38}$ Por su parte, los notables jerezanos procuraron revertir esta situación a través de la incorporación de su ciudad de un modo más intenso en los grandes circuitos comerciales, especialmente en el colonial. ${ }^{39}$ Para esto, en comunión con los mercaderes gaditanos, presionaron para que tanto Felipe III como Felipe IV convirtieran a la bahía en el antepuerto de la Carrera de Indias y facilitasen de este modo su participación en el comercio americano por medio de la construcción de un canal que uniera el Guadalquivir con el Guadalete, y que permitiera un vínculo fluvial entre Sevilla, Jerez y Cádiz. ${ }^{40}$

Situándose en esta línea, el memorial de Gaitán intentaba potenciar estos reclamos, cuyo origen podemos situar a principios del siglo XVII, conjugando sus gestiones en la corte con sus vínculos con algunos de los

37 Ibidem, 108-112.

38 Sobre la situación de Jerez en el siglo XVII véase: Sancho de Sopranis, III, 1969.

39 Díaz Blanco, 2012, 287.

40 Idem. La centralidad que en muchos proyectos de Gaytán posee la realización de canales y de obras hidráulicas de gran envergadura parece ser otro elemento presente en el ambiente intelectual, ya que el propio Olivares — retomando proyectos de la época de Felipe II — intentó hacer navegable el Tajo, desde Lisboa hasta Toledo, y luego el Jarama y el Manzanares hasta la Casa de Campo de Madrid. Marañón, 2006, 141, 285 y 406. 
miembros más destacados de la alta administración indiana. Es probable que durante su estancia en Madrid entre 1619 y 1620 haya sido este memorialista uno de los introductores del proyecto en el Consejo de Indias, ya que su presidente, Fernando Carrillo, tenía gran estima de su opinión sobre este asunto y, aparentemente, habrían tenido ocasión de debatir sobre él. ${ }^{41}$ Un tiempo después, en 1621, el monarca volvió a interesarse por incrementar la seguridad del despacho de las flotas de Indias, probablemente a instancias del conde de Castrillo, para lo cual solicitó el parecer de los ayuntamientos de Cádiz y Jerez, e incluso consultó la novedad con el duque de Medina Sidonia. ${ }^{42}$

Contando con varias de las opiniones solicitadas y con los memoriales técnicos de Alonso de Vandelvira y Julio César Fontanta, en los que además de aportar datos concretos para la construcción y financiación del proyecto se rebatían las objeciones de Sevilla, Felipe IV pidió asesoramiento al Consejo y a la Junta de Guerra de Indias en diciembre de $1622 .{ }^{43}$ Sin embargo, la oposición de Medina Sidonia y del comercio hispalense consiguió que el canal y el traslado de la cabecera de la Carrera de Indias a Cádiz quedasen estancados hasta 1624. Este año el monarca encargó a una partida de especialistas, de la que participó Gaitán, que volviera a analizar la viabilidad del canal. La comisión estuvo a cargo de Leonardo Turriano, pero también contó con la participación de varios opositores que terminaron imponiendo su parecer. ${ }^{44}$

Resulta claro que Gaitán buscaba reflotar este proyecto, que para ese momento se encontraba en una coyuntura desfavorable, de modo que aprovechando el impacto de las recientes pérdidas de navíos provocadas por el empeoramiento de las condiciones de navegabilidad de la barra de Sanlúcar, recomendó que el comercio colonial partiera y regresara a la bahía de Cádiz, «una de las obras que Dios previno en la creación del mundo para seguridad y descanso de los que andan por la mar». ${ }^{45}$ Este enclave ofrecía una navegación más segura y, sobre todo, acabar con la incertidumbre y las dilaciones en la partida de las flotas y los galeones, ya que para que las armadas pudie-

41 Gaytán, 1625a, 39.

42 Díaz Blanco, 2012, 288. Véanse los distintos pareceres en AGI, Indiferente, 615.

43 AGI, Indiferente, 615, Decreto de SM al Consejo y a la Junta de Guerra de Indias para que delibere acerca de la mudanza del despacho de las flotas y armadas de la Carrera de las Indias a Cádiz, Madrid, 24 de diciembre de 1622.

44 Gaytán, 1625a, 38. Para las comisiones véase: Pérez Escolano, 1989.

45 Ibidem, 34 
ran zarpar de Sanlúcar era preciso que la marea alta coincidiera con el viento favorable y se dispusiera de pilotos con experiencia.

Como complemento, volvía sobre la construcción del canal que introduciría de lleno a Jerez en el mundo de la Carrera de Indias y denunciaba explícitamente la intervención de algunos «aduladores del duque» de Medina Sidonia en un intento de obstaculizar el proyecto. La construcción del navillo, que debía comunicar las aguas de los ríos Guadalquivir, Guadalete y Salado de Puerto Real hasta hacerlas desembocar en la bahía de Cádiz, resultaría de «grande utilidad y provecho [...] a estos reinos y a los de las Indias y comercio de todos y el aumento de la Real Hacienda». ${ }^{46}$ Asimismo, favorecería el comercio de Sevilla, Cádiz y Jerez, y el aumento de la población, «que es la principal causa de riqueza de los lugares y los reinos». ${ }^{47}$ En consecuencia, no sería oportuno escatimar esfuerzos ni detenerse ante los obstáculos de una obra que por las características del terreno resultaba sencilla en términos técnicos, y cuyo financiamiento recaería en la ciudad de Jerez. Según Gaitán, la ciudad había acordado, «por mayor parte de votos que siguieron al mío», tomar a su cargo la realización del canal por dos millones de ducados, aunque el memorialista no tenía muy claro que ese fuera su valor final. Por este motivo, no dejó de recordar a Felipe IV que por mucho que costase el navillo, en realidad «se compra barato» por los beneficios enumerados, para luego hacer una encendida defensa del intervencionismo regio en el fomento del territorio. De hecho, recordaba que los

gastos que se hacen en obras pública no son costosos ni dañosos porque la gente popular se ocupa, gana dineros y con la asistencia al trabajo se excusan salteamientos de caminos y robos en los lugares y el dinero todo se queda en los mismos lugares pues en la comida y bebida se gasta lo más, y en estos géneros tiene su Majestad impuestos derechos reales que aumentan el valor de las rentas que tocará más a su Majestad en la contribución que el gasto que su Majestad tendría en esta obra. ${ }^{48}$

\section{El flujo mercantil transatlántico: defensa y fraude}

Los memoriales de Gaitán no ciñen su atención a la cabecera de la Carrera de Indias, sino que proponen una visión de conjunto del flujo mer-

46 Ibidem, 38.

47 Ibidem, 37

48 Ibidem, 38. 
cantil transatlántico que, partiendo del descenso de las remesas reales, «donde se ve muy bien lo poco que cada año viene a Su Majestad», se concentraban en las dificultades experimentadas por la navegación transatlántica. Esta, sin embargo - siempre según este autor - continuaba manifestando una gran vitalidad que se expresaba «en lo mucho que viene en cada flota a particulares sin lo que viene por registrar y en cabeza de diferentes dueños registrado mal».49

Su obra resalta particularmente los problemas de seguridad del viaje, tanto por las deficiencias de la organización militar como también por las dificultades de planificación en el despacho anual de las flotas y los galeones, que en el caso de la de Tierra Firme vinculaba con la proliferación del contrabando.

Gaitán escribió sus arbitrios en un contexto en el que el incremento de la presencia enemiga en América, especialmente en el Caribe, el océano Pacífico y el Brasil portugués, estaba generando la necesidad de atender a una nueva realidad marcada por la acentuación del desafío al exclusivismo territorial que habían disfrutado castellanos y portugueses. ${ }^{50}$ En concreto, el siglo XVII resultó decisivo para la configuración territorial de la América colonial, que se zanjó con la «internacionalización» del continente dada por la presencia de franceses, ingleses y holandeses. Sin embargo, a partir de principios de la década de 1620, con la ruptura de la Tregua de los Doce Años, la situación se volvió más compleja, ya que el desafío que plantearon estos últimos a los dominios ibéricos, en el marco de un conflicto disputado a escala mundial, se canalizó por medio de la Compañía de las Indias Occidentales que fue capaz de organizar operaciones militares de gran envergadura, algunas de las cuales persiguieron la conquista de núcleos ya existentes o el asentamiento en sitios estratégicos. En este contexto cabría mencionar que para el momento en el que Gaytán publicó su obra, la rivalidad hispano-holandesa se había reactivado en la Punta de Araya, en la vertiente pacífica de los virreinatos americanos, donde una poderosa escuadra atacó El Callao, Guayaquil y Acapulco, en Bahía y en Puerto Rico. ${ }^{51}$ Además, habría que señalar el incremento de la presencia de bucaneros y filibusteros que durante el segundo cuarto del siglo XVII dieron forma a una piratería americana desvinculada de la tutela europea. ${ }^{52}$

49 Ibidem, 23-24.

50 Sobre este tema véase: Amadori, 2013, 377 y ss.

51 Israel, 1997, 119 y ss.

52 Lucena Salmoral, 1992. 
Gaytán había apreciado la situación de primera mano a raíz de su viaje a la gobernación de Venezuela, y además poseía información muy precisa acerca de los múltiples intentos que se habían realizado para acabar con el problema, tanto en el ámbito local como en el Consejo de Indias. Su principal propuesta se inscribe en un largo debate cortesano acerca de la necesidad de establecer una escuadra permanente en el Caribe, proyecto que se consideró desde principios del siglo XVII y que recién se concretó en 1641, a raíz de su elevado coste de mantenimiento en las Indias. ${ }^{53}$

Para este autor, era preciso abandonar las soluciones coyunturales o de corto alcance, como se habían ensayado en el pasado, ya que su coste llegaba a ser superior al de unas fuerzas estables y su efectividad reducida. En su lugar, debían establecerse tres pequeñas escuadras, dos conformadas por un patache y dos navíos cada una, y la otra por cuatro navíos y dos pataches, con asiento en Cartagena, La Habana y Puerto Rico respectivamente. La plaza de San Juan, que había resultado seriamente dañada por el ataque holandés, era propuesta como un lugar clave del nuevo sistema defensivo en función de su ubicación a barlovento, de las bondades de su puerto, de la proximidad de las islas Dominicas y de la facilidad de comunicación con España. ${ }^{54}$ De este modo, las escuadras podrían acudir rápidamente allí donde se recibieran noticias de presencia enemiga, dándole una versatilidad al aparato defensivo del que carecería si, como se debatía en la corte y finalmente se dispuso, la armada fuese una sola de gran poderío. Reconocía Gaitán que la capacidad de las escuadras podría incrementarse fácilmente ante cualquier necesidad mediante la incorporación de uno o dos navíos armados en los puertos en donde asistían o a través del envío de refuerzos desde España que guardasen relación con la envergadura de la amenaza.

Cada una de las escuadras debía realizar un recorrido determinado que, en coordinación con la periodicidad de las flotas y los galeones, permitiera asegurar las llaves del Caribe. Así, la de Puerto Rico saldría de su apostadero entre enero y febrero para encontrarse con la flota en las islas Dominicas, desde donde la acompañaría a Cartagena y Portobelo para regresar luego a La Habana. La armada de Cartagena, por su parte, tendría a su cargo el control de un extenso sistema de comercio regional que también enlazaba con la ruta de las flotas, ya que debía escoltar a los navíos que en el mes de febrero conducían los frutos de la «costa de Tierra Firme

53 Torres Ramírez, 1981; Amadori, 2013, 420 y ss.

54 Para el ataque a San Juan y las obras defensivas realizadas durante la primera mitad del siglo XVII, véase: Vila Vilar, 1974, 175 y ss. 
que es desde la Trinidad, la Margarita, Cumaná, Caracas, Coro, la laguna de Maracaibo, Río de la Hacha y Santa Marta y otros que salen del Río Grande de la Magdalena de manera que se va conduciendo la harina, tabaco, corambre, cacao y otros géneros que se gastan en Cartagena y trae la Flota de Tierra Firme». Asimismo, su presencia garantizaría la navegación de las fragatas y los barcos que salían de dicho río interesados en el oro y plata del Nuevo Reino. Por último, la escuadra de La Habana debía movilizase en mayo hacia el cabo de San Antón para proteger los navíos que acudían a dicho puerto para proveer a las flotas y a los galeones. También tendría que escoltar a las naos de Honduras y hacer algunas otras salidas para llevar los situados a Florida y Santo Domingo..$^{55}$

La dotación de las nuevas embarcaciones procedería de los presidios de Cartagena, Puerto Rico, La Habana, Santo Domingo y Portobelo, reduciendo a la mitad los efectivos estables. Pese a esto, Gaitán consideraba que la capacidad defensiva no solo no se reduciría sino que incluso se incrementaría, porque la presencia de las escuadras en el mar disuadiría a los enemigos de echar gente a tierra, y además las condiciones del servicio en la flota seleccionarían a los individuos con auténtica vocación militar. De este modo, las plazas defensivas dejarían de estar en manos de los criados $\mathrm{y}$ «bienhechores» de los gobernadores y de los oficiales reales, revirtiendo una situación que por estos años no solo fue denunciada sino también perseguida desde el poder central que procuró aumentar la eficacia de los dispositivos militares de la monarquía. ${ }^{56}$ Con esta modificación, por tanto, aunque el número de efectivos de los presidios se redujera a la mitad, la mejora cualitativa de los soldados supondría un incremento de la capacidad defensiva indiana.

Probablemente el punto menos consistente del proyecto defensivo caribeño sea el de la financiación, ya que no aportaba cifras concretas, pese a que Gaytán afirmaba que las nuevas embarcaciones se sostendrían sin necesidad de aumentar los aportes de la Real Hacienda. El dinero necesa-

55 Gaytán, 1625a, 25-33.

56 Ibidem, 32. En sintonía con la necesidad de adecuar el aparato defensivo a las nuevas circunstancias y de acuerdo con el objetivo del régimen de Olivares de restaurar el poderío de las armas de la monarquía, desde Madrid se encomendó en varias oportunidades que las provisiones de los oficios militares se realizaran en personas idóneas, concretamente en «militares» en quien con satisfacción se pueda fiar" la defensa de las Indias. Véase: AGI, Indiferente, 617, Decreto al Canciller de Indias sobre la provisión de las plazas militares. Madrid, 19 de marzo de 1629; Archivo General de Palacio, Mss. II/1629, Real Cédula para que no se asienten a ningún criado de ministros plazas militares en los puertos y presidios de las Indias, Madrid, 23 de febrero de 1627, 293-294. 
rio se obtendría de la supresión de las cuestionadas galeras de Cartagena, ${ }^{57}$ del ahorro en el traslado de los situados entre la Nueva España, las islas de Barlovento y la Florida, y de la aplicación de algunos derechos navales ya existentes. Además, junto con el aumento de la presencia militar en el Caribe se produciría un incremento de los tratos, y con ellos del beneficio para las arcas reales.

Gaytán añadía a su programa de mejora de la seguridad del sistema de flotas y galeones la propuesta de alterar las fechas de salida hacia América y de arribo a la península. En este caso, los motivos de estos cambios no son de naturaleza militar, sino que respondían a las condiciones climáticas, a la necesidad de reducir el coste de los galeones de la plata y a evitar el fraude, siendo esta última su prioridad.

Según el memorialista, la flota de Tierra Firme, cuya partida solía producirse en abril e incluso en marzo con el argumento de que fuera acompañada por los galeones, debía salir de Cádiz en enero. Atribuía el retraso, que provocaba que la flota se encontrase frecuentemente con condiciones complicadas de navegación, al fraude cometido por los generales, almirantes y capitanes de los navíos de protección, que cargaban mercancías no registradas y libres de imposiciones fiscales, que luego vendían en Cartagena y Portobelo durante los pocos días que recalaban en esos puertos por la prisa de regresar a tiempo. De este modo, los mercados se proveían rápidamente de mercancías baratas, lo que dificultaba la colocación de lo que habían acordado enviar los cargadores de Sevilla. Gaytán atribuía al menor precio y a la primacía con la que se descargaban estas mercancías el descenso de la venta de productos remitidos por los cargadores hispalenses, que se estaba dejando sentir ya en los mercados americanos por los cambios en las economías coloniales y por el exceso de oferta. Como resultado de esta contracción en el trato, la composición de la flota se había ido reduciendo hasta las seis embarcaciones anuales. ${ }^{58}$

Para atenuar esta situación, la flota de Tierra Firme debía, como se ha dicho, salir en enero sin acompañamiento de los galeones, ya que en esta fecha no había riesgo de sufrir ataques y tormentas, y encontrarse con la escuadra de Indias en las islas Dominicas. De este modo, dispondría del tiempo suficiente para asegurar mejores condiciones de venta a los cargadores sevillanos y regresar a La Habana en el mes de julio para reunirse con la

57 Gaytán, 1625a, 27.

58 Ibidem, 44 
flota de la Nueva España y con los galeones para regresar a la península. Esta última, por su parte, debía partir en mayo, en compañía de los galeones, para evitar las tormentas en el área del Caribe y estar de regreso en La Habana en julio del año siguiente, luego de haber invernado en las Indias. ${ }^{59}$

\section{La defensa del Estrecho de Gibraltar y los galeones de Indias}

El carácter sistémico y transatlántico del arbitrismo de Gaytán le condujo a vincular la defensa del comercio colonial con un proyecto de gran calado destinado a controlar el Estrecho de Gibraltar - asunto debatido e intentado ya durante los reinados de Felipe II y Felipe III- y a incrementar el poderío de los galeones de la plata, que prometía «no echar en los reinos nuevos pesos, antes quitar algunos de los que hoy se pagan y minorar otros».$^{60} \mathrm{El}$ punto de partida de esta propuesta consistía en la creencia de que la formación de una poderosa flota de cien embarcaciones que resguardase el Estrecho convertiría a Felipe IV en «el señor del mar y de sus enemigos», inclinando definitivamente la balanza del conflicto internacional de las armas hispánicas. ${ }^{61}$

Como un producto de la curiosa síntesis entre reforma y restauración, entre innovación y tradicionalismo, que atraviesa la obra de Gaytán hay que señalar su idea de que fueran las Órdenes Militares las que se encargasen de la guarda del Estrecho. ${ }^{62}$ Por medio de la restitución de la función original de estas organizaciones, no solo se devolvería el sentido primigenio a los hábitos y, sobre todo, a las propiedades otorgadas en su momento por los monarcas. Además, el reino evitaría tener que afrontar las gabelas que se le pretendían imponer para la financiación de dicha armada. En consecuencia, los presidios de Orán, Alarache y la Mámora debían ser sustituidos por conventos de las órdenes de Santiago, Calatrava y Alcántara respectivamente, que tendrían a su cargo la defensa del territorio y la gestión

59 Ibidem, 41-50.

60 Ibidem, 60.

61 «El rey que es señor de [el Estrecho] es de todo el mundo, pues está en medio y por donde trajinar y comerciar las mercaderías del norte a Levante que si los reyes de Francia, Inglaterra y las demás de septentrión y potentados de Italia y Alemania». Gaytán, 1625a, 116. Sobre los proyectos y los intentos de aumentar la presencia de las armas hispánicas en el Estrecho durante el reinado de Felipe III, véase: García García, 1996, 97 y ss.

62 Para la Órdenes Militares durante el siglo XVII y su relación con el poder central véase: Postigo Castellanos, 1988 y Ruiz Rodríguez, 2001. 
de la flota. Gaytán tenía en su cabeza el modelo de los caballeros de San Juan, es decir, de la Orden de Malta, y sugería la adopción de una pauta de servicio que suponía un cambio radical en el sentido y la función que habían adoptado los hábitos y las encomiendas de las órdenes castellanas. Quienes pasaran a servir en los conventos-presidios no serían caballeros sino aspirantes, ya que resultaría necesario asistir durante seis años, dos en tierra y cuatro en mar, para recibir el hábito y, naturalmente, para poder aspirar a una encomienda. De modo que el servicio en el estrecho se convertiría en una escuela de virtud y templanza, y en el período de prueba de los futuros caballeros. ${ }^{63}$

La armada del Estrecho debía conformarse de sesenta y cuatro navíos grandes, dieciséis pataches y doce galeras, y ponerse bajo las órdenes de un solo general que también tendría el control de los presidios. Para asegurar la construcción y el mantenimiento de una flota tan numerosa Gaytán concibió - como se verá más adelante — un ingenioso plan de desarrollo local en Venezuela, en torno a las minas de cobre y al astillero que aspiraba a instalar en Borburata, en el que despliega toda su creatividad como autor.

De hecho, una parte fundamental de este proyecto es la que compete a las Indias, ya que los galeones que debían acudir por la plata acompañando a la flota de la Nueva España, para luego recoger a la que regresara de Tierra Firme, procederían de la armada del Estrecho. Esta circunstancia favorecería el control del fraude realizado en los navíos militares, ya que estos últimos evitarían tocar los puertos de Sevilla, Cádiz y Sanlúcar, y además - dado que en el Estrecho había un conjunto importante de naves pertrechadas - los capitanes, pilotos y maestres seleccionados para realizar la singladura atlántica serían informados con muy pocos días de antelación. Asimismo, la reducción de los meses de navegación a solo cuatro permitirá aplicar parte del dinero a la financiación del incremento del número de navíos armados, e incluso reducir la avería al $3 \%$ para desincentivar el ocultamiento de plata y mercancías, y aumentar los ingresos fiscales. En total, el proyecto contemplaba que la flota de regreso contara con doce galeones, resultado de los cuatro que irían de la península pertenecientes a la Armada del Estrecho, los otros cuatro fabricados anualmente en América y también las capitanas y almirantas de las flotas de la Nueva España y Tierra Firme. ${ }^{64}$

63 Gaytán, 1625a, 112-116, 131-132.

64 Ibidem, 122-124. 
La financiación de la construcción y el mantenimiento de la escuadra, así como el de los presidios y conventos debía obtenerse de varias fuentes. La propuesta de Gaytán consistía en la aplicación del $6 \%$ de avería y de los excusados que la Iglesia ofrecía para la paga y el sustento de las galeras. Sugería, además, que se destinaran bienes y haciendas de las Órdenes Militares para afrontar los gastos de los conventos y de las encomiendas, y aplicarse al pago quienes servían en la armada.$^{65}$ Los diezmos obtenidos con la promoción de la agricultura en Murcia también tendrían que destinarse a afrontar este gasto defensivo, junto con las presas de mar que consiguiera la armada. Habría que añadir, finalmente, que el producto de la venta de las cuatro embarcaciones desechadas por las renovaciones anuales que planificaba Gaytán se aplicaría también a la construcción y armado de nuevos galeones.

\section{Desarrollo local, fiscalidad y defensa: entre Murcia y Venezuela}

Uno de los aspectos más peculiares del arbitrismo de Gaytán radica en la envergadura de algunos de sus proyectos, que se desmarcan de las soluciones coyunturales para llegar a proponer complejos planes de desarrollo regional, encaminados a revertir la decadencia de la monarquía, asegurar la posesión territorial por parte de la Corona, mejorar la defensa, incrementar la población, disminuir las cargas fiscales y las gabelas, y aumentar los ingresos de la Real Hacienda. De hecho, aquí se manifiesta claramente la complementariedad con la que Gaytán concebía la relación entre las distintas regiones de la monarquía. Claro que la perspectiva desde la que elabora sus arbitrios es la de la metáfora organicista, enfatizando la necesidad de encontrar un equilibrio, siempre complicado en la práctica aunque perfectamente plausible según sus memoriales, entre unos ingresos fiscales capaces de sustentar la política exterior de poder de la corona y el desempeño de los reinos. En concreto, el autor adopta una racionalidad «desarrollista», al decir de José Javier Ruiz Ibáñez, que procuraba que la acción de la corona en el ordenamiento económico interno se tradujera también en su propio beneficio. ${ }^{66}$

65 Ibidem, 131.

66 Ruiz Ibáñez, 1995, 290. 


\section{El regadío de Murcia, Lorca y Cartagena}

En la península, esta búsqueda de una base fiscal más estable y de unas fuentes de riqueza más sólidas que las del oscilante comercio colonial que Gaytán tenía en mente, se centraron en el reino de Murcia que, a raíz de la expulsión de los moriscos, vio afectados algunos sectores de su economía y sufrió un apreciable declive demográfico. ${ }^{67}$ En concreto, el arbitrista presentó un plan de desarrollo regional consistente en la realización de obras hidráulicas que permitieran el riego de los campos de Murcia, Lorca y Cartagena. Para ser precisos, hay que puntualizar que este arbitrio no era de su autoría, sino que es muy probable que durante su estancia en la corte hubiera tenido conocimiento del memorial que presentó el capitán Pedro Agustín de Abarca a la cámara de Castilla, con el que su propuesta tenía muchos — demasiados - puntos en común. ${ }^{68}$ La construcción de obras de regadío en esta región ya había sido objeto de sólidos planteamientos desde tiempos de Felipe II, que incluso en 1587 llegaron a cuajar en un intento fallido de ejecutarlas. Ya en el siglo XVII, a finales de la década de 1610, las reclamaciones de las ciudades fueron articuladas en el citado memorial de Abarca, que nuevamente se saldó con otra comisión, esta vez a cargo del licenciado Gregorio López Madera, que no consiguió su cometido por la oposición de las oligarquías locales y por la falta de acuerdo entre las diversas instancias institucionales implicadas. ${ }^{69}$

Pese a las dificultades, Gaytán consideraba que la obra hidráulica era perfectamente factible y con un coste de 400.000 ducados — que debía afrontar la Corona, discrepando en este punto con Abarca, que hacía recaer el gasto en los lugares beneficiados por el regadío-, hasta el punto de permitir el riego de un millón de fanegas de tierra que debían destinarse, fundamentalmente, a la producción de trigo y cáñamo para las jarcias de las embarcaciones. A raíz de la falta de labradores, las labores agrícolas se realizarían con el apoyo de mano de obra esclava que los productores comprasen a los mercaderes lusos en Lisboa. Como resultado, el incremento de la superficie cultivable no solo propiciaría la riqueza del reino de Murcia, sino que además generaría unos ingresos estimados en 2 millones de ducados anuales, cuya cuarta parte se destinaría a la financiación de la armada del

67 Sobre la situación del reino de Murcia en este período, véase: Chacón Jiménez, 1980.

68 Para la descripción del proyecto de Abarca, véase: Burgos Esteban, 1995, 92 y 93.

69 Sobre los sucesivos proyectos para la construcción de canales de irrigación y especialmente para las alternativas generadas por el memorial del capitán Abarca, véase: Idem. 
Estrecho. Con la restricción de la importación de trigo y cáñamo, la corona establecería las condiciones para que permaneciese «entre nosotros la riqueza que al paso que se aumentare y retuviere el oro y plata en España se disminuye el trato y comercio con los extranjeros y será causa para desavecindarse muchas personas de otros reinos y venir a vivir y poblar los de Castilla, mayormente si el Estrecho de Gibraltar está con la guarda y defensa que he dicho pues los frutos de los campos que voy tratando tendrán facilidad y seguridad para conducir a Portugal y Andalucía». Asimismo, la corona debía intervenir prohibiendo el cultivo de ciertos productos, como las viñas, para asegurar el efecto multiplicador de la dependencia entre las regiones, ya que lo importante para los

reinos es tener dentro de si todo lo necesario y las provincias de que se componen los reinos sean abundantes de un género necesario y necesiten de otro para que los mercaderes y personas que las comercian los carros, recuas y navíos con que trajinan los frutos y mercaderías de unos a otros, anden siempre cargados y tengan fletes y retornos donde quiera que fuera para que los fletes y portes sean más baratos y abaje el precio de las mercaderías, pues en el que tienen y da el último consumidor de ellas es mediante lo que cuestan de labrador y obrador y de allí van creciendo en precio conforme los derechos y costas que se van cargando en ellas de fletes y de acarreos y en esto consiste el aumento del comercio, reinos y provincias y de la Real Hacienda pues en las ventas y reventas, pasos y entradas de puertos están situados los derechos reales. ${ }^{70}$

\section{El desarrollo del norte de Venezuela}

El segundo gran proyecto de desarrollo local de Gaytán se ubica en un amplio espacio circundante al puerto de Borburata, ubicado en la costa norte de la actual Venezuela. Este plan tenía su base en las minas de cobre de la serranía de Cocorote, aunque apuntaba al desenvolvimiento de diversas industrias de la zona, y poseía el atractivo de responder a varias necesidades del monarca por medio de la concatenación de proyectos particulares muy propia del arbitrismo. Gaytán procuraba no solo satisfacer la demanda de cobre que había en la península, tanto para la acuñación de moneda como para la fábrica de artillería, ${ }^{71}$ sino también los requerimientos defen-

70 Gaytán, 1625a, 138.

71 Véanse los decretos de Felipe IV al Consejo de Indias para que se envíe con toda rapidez parte del cobre producido en Cuba, Chile y «a donde hubiere noticias que le hay». AGI, Indiferente, 615, Decretos de Felipe IV al Consejo de índias, Madrid, y Aranjuez, 18 de febrero y 21 de abril de 1822 . 
sivos de la monarquía en su conjunto. Asimismo, buscaba el fomento del espacio local y el incremento de los ingresos fiscales. Según sus propias palabras, «dichas minas son bastantes para lo que se pretende, y hay todo lo que la imaginación pueda desear para el manejo y beneficio de tan gran riqueza, y todas las cosas tan en su lugar, que admira, dándose la mano las unas con las otras, no sólo para este intento sino para otros del aumento de la Real Hacienda, fortificación y defensa de estos Reinos de Castilla e Indias $[\mathrm{y}]$ haciéndose las fundaciones y labores de dichas minas, se facilitan y acomodan las demás». ${ }^{72}$

Principalmente debía asegurarse el establecimiento en torno a las minas de Cocorote de seis hornos, cinco ingenios y todo lo necesario para mantener en funcionamiento unos yacimientos capaces de producir cien quintales de cobre diario, lo suficiente para «lo que estos Reinos de Castilla pueden gastar y consumir en labor de moneda, fundición de artillería y gasto ordinario». ${ }^{73} \mathrm{El}$ memorial de Gaytán ofrece una minuciosa enumeración de la cantidad y cualidades de las cuatrocientas sesenta personas que debían encargarse de la fábrica, desde el gobernador y su teniente, pasando por el alcalde y el capellán mayor, hasta la mano de obra indígena y esclava. ${ }^{74}$ Toda esta gente se asentaría junto a las minas «en forma de ciudad», contando con justicia y cabildo que los gobernase. Para su aprovisionamiento, el arbitrista proponía la siembra de maíz en torno a la ciudad, el establecimiento de una hacienda dedicada a la cría de ganado vacuno en la provincia de Nirgua, donde debía establecerse el segundo asentamiento de los tres propuestos por Gaytán, y la obtención de pescado y sal en Tucacas. ${ }^{75}$ Junto con la producción de cobre, la ocupación del territorio cercano a las minas ofrecía el atractivo de permitir el aprovechamiento de varios yacimientos de oro que no estaban productivos por la amenaza de los indígenas, que de esta manera recibirían el beneficio de la evangelización, y por la falta de mano de obra que se subsanaría con la importación de esclavos. Con todo, el valor de este asentamiento minero para la Real Hacienda, incluidos los fletes de los materiales importados de Europa y los esclavos de Lisboa o Cabo Verde, sería de 130.000 ducados. $^{76}$

\footnotetext{
72 Gaytán, 1621, 1r.

73 Idem.

74 Ibidem, 5r-9r.

75 Ibidem, $4 \mathrm{v}$.

76 Ibidem, 9 r.
} 


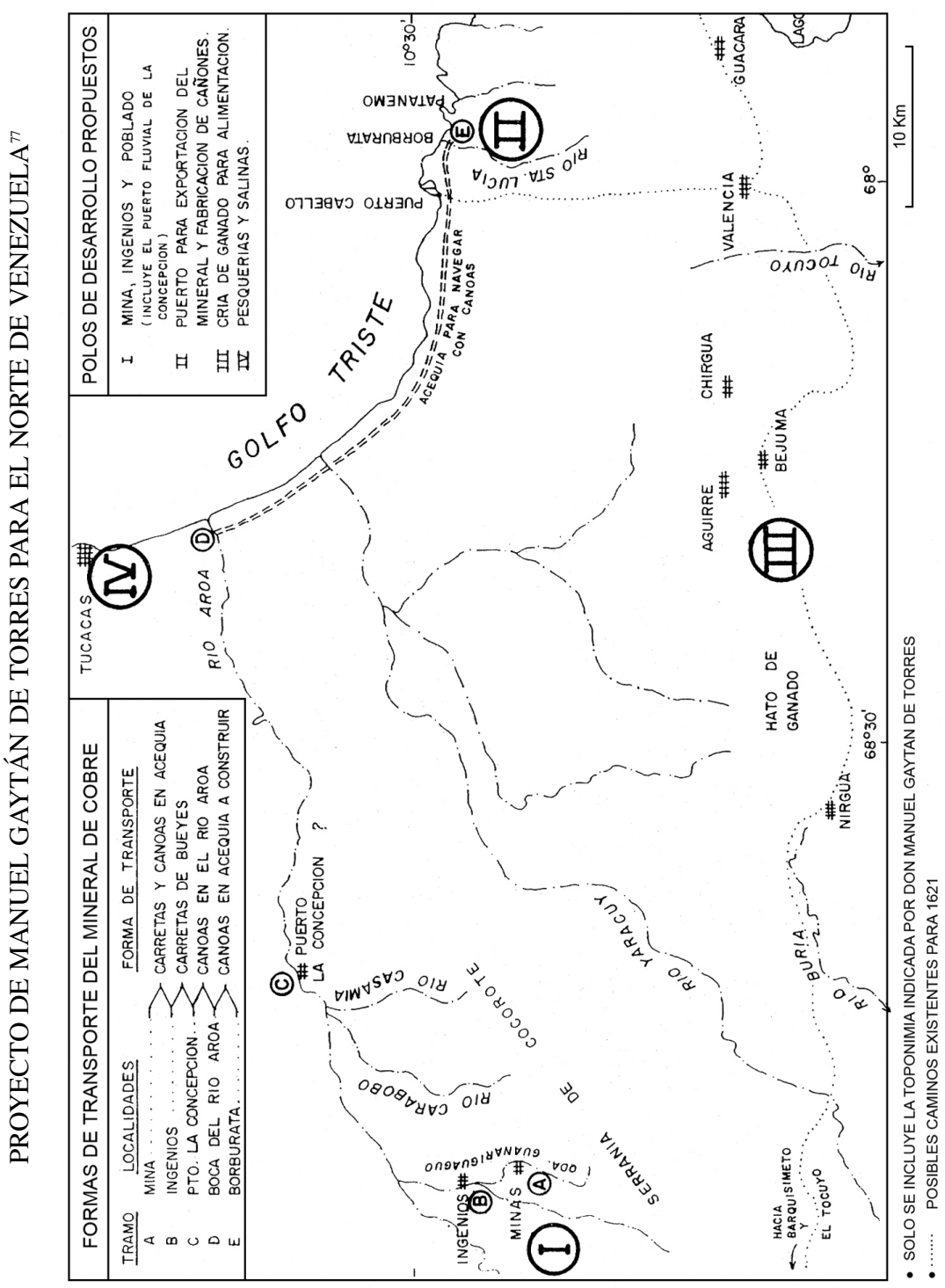


Luego, Gaytán concebía el establecimiento de un tercer asentamiento en el puerto de Borburata, junto a Puerto Cabello, que debía funcionar como astillero y como vía de comunicación de la región con el exterior. El enclave, situado en un lugar privilegiado que lo convertía en un puerto excelente, debía cercarse para cobijar con seguridad los almacenes de cobre y la fábrica de navíos. De hecho, el metal producido en Cocorote debía trasladarse hasta Borburata por el río Aroa y luego por una acequia que bordeara el Golfo Triste, evitando así una navegación riesgosa por el Caribe. ${ }^{78}$ El metal se almacenaría en aquel puerto, donde aguardaría a la flota que lo recogería para llevarlo a la península.

En Borburata se producirían cuatro galeones de quinientas toneladas con toda su artillería por año - cien piezas en total—, para proveer de nuevas embarcaciones a la armada del Estrecho. Gaytán calculaba el valor de cada embarcación artillada en 14.204 ducados, mientras que estimaba que la venta en América de los navíos desechados por la armada sería de entre dieciocho y veinte mil, con lo cual prácticamente se saldaría la operación sin ningún gasto para la Real Hacienda. ${ }^{79}$

El aprovisionamiento del astillero también dependía de un arbitrio original, puesto que el memorialista proponía que cada año cuatro embarcaciones de la armada realizaran el viaje hacia Venezuela, llevando los pertrechos necesarios que no se dispusieran en Indias, junto con los marineros, los soldados y la oficialidad para ocho naves. De este modo, los cuatro galeones que se fabricasen a lo largo del año dispondrían de una tripulación y podrían acompañar a los cuatro remitidos desde España, aprovechando su viaje de ida hacia América para llevar a Borburata los elementos con los que se armarían los buques del año siguiente. Las ocho naves resultantes incrementarían su poderío defensivo con las almirantas y las capitanas de las flotas con que se reunirían en Cuba, alcanzando una capacidad defensiva considerable. ${ }^{80}$

La elección de este sitio para establecer la fábrica está relacionada con la mayor calidad de los barcos confeccionados en América en virtud de las maderas utilizadas, el menor valor de construcción a raíz de la naturaleza de su plan, y la disponibilidad de recursos: maderas nobles, cobre y, en el futuro, cuando el asentamiento de Nirgua prosperase, posiblemente jarcia y

78 Ibidem, 3v-4r.

79 Ibidem, 15v. Sobre las cualidades de los navíos americanos, Serrano Mangas, 1989, 41 y ss.

80 Las dificultades para disponer de la protección necesaria para la Carrera de Indias pueden verse en: Serrano Mangas, 1989, 49 y ss. 
algodón para los cabos y velas. La mano de obra procedería de los esclavos enviados expresamente y de las comunidades que se establecerían en el entorno. Estas últimas serían las encargadas de construir el castillo para almacenar el cobre y también la acequia desde el río Aroa hasta Borburata. El desarrollo de este puerto serviría, además, para alcanzar una solución al sistema de comercialización del tabaco, ya que debería albergar una feria a la que acudiesen los productores de toda la región y luego asegurar su embarcación a la península. ${ }^{81}$ Asimismo, en Borburata se establecería la fundición de las piezas de artillería para armar las doce embarcaciones, ya que no solo se dispondría de todo lo necesario - a excepción de estaño, hierro y acero- sino que también resultaría menos costoso que en Sevilla. ${ }^{82}$

\section{El problema de la fuga de la plata}

Una cuestión esencial dentro del planteamiento mercantilista de Gaytán es el de la moneda. Hemos visto ya su intención de incrementar la producción de las minas americanas mediante la reducción de los quintos mineros. Asimismo, confiaba en asegurar la intervención de la corona, que debía aprovechar el acceso a las fuentes de esclavos que brindaba la unión de las coronas y comprar dos mil piezas para entregarlas fiadas a los mineros. De este modo buscaba atenuar el impacto del declive demográfico indígena, al cual adjudicaba el descenso de la fiscalidad minera. Los esclavos, que tendrían que dirigirse tanto a la Nueva España como al Perú, podrían abonarse por los productores en dos años, que el memorialista consideraba suficientes para que el minero obtuviera más de lo que habían costado. ${ }^{83}$

Pero su principal aporte a la cuestión monetaria se produjo en el marco de los debates generados por la famosa propuesta del capitán Tomás de Cardona. Se trató de un arbitrio que generó una gran controversia en el contexto reformista experimentado entre finales del valimiento de Lerma e inicios de la primacía de Olivares ${ }^{84}$ Cardona, vinculado a los cargadores del consulado de Sevilla, había propuesto que del marco de plata enviado de las Indias, valorado en 65 reales, se acuñasen 84 reales de 34 maravedíes,

81 Gaytán, 1621, 20r y ss.

82 Ibidem, 16v-17v.

83 Gaytán, 1625a, 91-95.

84 Sobre el debate generado en torno a la modificación del valor de la plata, véase: García Guerra, 2003, cap. IV. La propuesta del capitán Cardona en Vilar Berrogain, 1978. 
en lugar de concederlo a los extranjeros por el primer valor. Es decir, una subida del marco de 19 reales como asegura Gaytán —una devaluación en realidad-, que pasaba a tener menos peso. ${ }^{85}$ Según Cardona, esta medida ofrecería a la Real Hacienda y a los vasallos del reino unas ganancias de seis millones de ducados anuales. ${ }^{86}$

Para Gaytán, en cambio, la subida de diez maravedíes por real resultaba excesiva y perjudicaría a los poseedores de moneda de vellón. Su propuesta pasaba por cercenar seis maravedíes por real, para luego convertir nuevamente los 28 maravedíes restantes en 34. De este modo, con la disminución del 22,5\%, no se perjudicaría a la moneda de cobre y, por lo tanto, tampoco tendría necesidad el monarca de satisfacer a los vasallos, aumentándose así el beneficio que podría obtener del arbitrio. En suma, el real modificado alcanzaría

su justo valor y el que se le debe dar para que sean corrientes los tratos, y valiendo treinta y cuatro [...] cesan estos inconvenientes y resulta un bien universal a V.M. y a esos reinos, que por la mucha plata que en ellos hay será bastante la cercenadura de la moneda que hoy está acuñada para desempeñar a V. Majestad, y dejar estos reinos para lo futuro con alimento, y menos gabelas de las que hoy tienen, y se impedirán todas las cautelas y medios que los extranjeros tienen para sacar la plata. ${ }^{87}$

Es decir, que la cercenadura del real impediría la saca de plata de Castilla, dando lugar a que los mercaderes extranjeros empleasen sus ganancias en productos de la tierra que no solo beneficiarían al reino, sino que además incrementarían los ingresos fiscales. Incluso, para preservar la plata dentro del reino Gaytán llegó a plantear el supuesto de que los enemigos de la monarquía también alterasen su valor. En ese caso, recomendaba que

todo lo que procediere de las mercaderías, que en estos reinos los extranjeros entraren, den fianza en las aduanas antes de sacarlas, que dentro de seis meses, la cantidad que montare lo procedido de sus mercancías, conforme al afuero del vista, emplearán en otras de estos reinos, y sacarán de ellos, y con esto se obviará de todo punto la codicia que tienen por sacar plata. ${ }^{88}$

Su programa recogía la intención de reducir los gastos provocados por el uso de asentistas para financiar la maquinaria militar de la monarquía.

85 Gaytán, 395r.

86 García Guerra, 2003, 148 y ss.

87 Gaytán, 395v.

88 Ibidem, 397v. 
En su lugar, Gaytán proponía enviar el dinero en las armadas reales para ahorrar los intereses. ${ }^{89}$ Con los ingresos obtenidos de esta reforma, debería procederse al desempeño de la Real Hacienda mediante el pago de las deudas, sobre todo de aquellas contraídas en forma de juros, con lo cual se conseguiría propiciar la riqueza de los vasallos, quienes aplicarían sus bienes a labores productivas o mercantiles que aumentarían los tratos y con ellos las alcabalas y los almojarifazgos. Todo esto en el marco de un proteccionismo que impidiese el ingreso en la corona de Castilla de frutos, géneros e incluso de manufacturas elaboradas en Francia, Inglaterra y Flandes. Incluso, «de tratar y navegar los vecinos de estos reinos, y valerse y sustentar de estos modos y ganancias se vienen a quitar a los extranjeros, que tan poderosos están de navíos, marineros, y dineros, y de otras muchas dependencias, que esto trae, pues de un bien se siguen otros muchos, y lo mismo por lo contrario»..$^{90}$ Entre esos «muchos» bienes se encontraba la promoción de la industria naval. ${ }^{91}$

Su intento de preservar la plata dentro del mundo hispánico se expresó también en un arbitrio que recomendaba la prohibición del comercio de México con Filipinas, y su sustitución por un periplo mercantil que partiera desde la península. De este modo no solo se evitaría «una de las mayores sangrías que tiene la plata de la Nueva España», sino que también se mantendría un contacto más fluido con aquella parte del imperio, lo que a su vez permitiría responder mejor a cualquier ataque enemigo y convertirlo en un destino de servicio más atractivo. ${ }^{92}$

Esta medida se complementaba con otras destinadas a hacer aflorar los metales descaminados que se dirigían fuera del reino, a asegurar el cobro de los derechos correspondientes y, sobre todo, a reforzar la efectividad de la reducción del valor del real. Así, Gaytán reclamaba la prohibición en las Indias de tratar y contratar con barras de oro y plata, sino solo en metal acuñado, y que los metales se ensayasen inmediatamente, para lo cual sugería agilizar el sistema de amonedamiento. ${ }^{93}$

89 Ibidem, 396r-398v.

90 Ibidem, 398r.

91 Idem.

92 Gaytán, 1625a, 60-65. La preocupación por la fuga de plata hacia el Extremo Oriente es una cuestión que aparece con asiduidad en el arbitrismo cortesano de finales de la década de 1610 y principios de la de 1620. Véase: Memorial de Pedro Hurtado de Alcocer a Felipe IV, 9 de diciembre de 1621, en González Palencia, 1932, 175 y ss.

93 Gaytán, 1625a, 87-91. 


\section{A modo de conclusión: un proyecto mercantilista de plasmación transatlántica}

A diferencia del desencanto que, por diversos motivos, en ciertos sectores de la sociedad castellana estaba comenzando a despertar la posesión de los reinos americanos, Gaytán estaba plenamente convencido de que las Indias seguían siendo uno de los baluartes de la monarquía, sin el cual resultaría prácticamente imposible revertir la situación de la Real Hacienda y restituir el poder del monarca. Pero frente a la voracidad fiscal y a las imposiciones sobre las arcas reales que se acentuaron a partir de mediados de la década de 1620 por los compromisos militares y políticos de una estrategia dinástica de poder, Gaytán vislumbraba el largo plazo. En lugar de preferir el tiempo político y coyuntural del valido, que a su pesar se vio obligado a multiplicar las cargas de los reinos de cara a obtener una victoria sobre sus enemigos que permitiera poner en ejecución un proyecto reformista, el arbitrista vislumbró un futuro menos inmediato en el que procuró restaurar tanto el poder de Felipe IV como la riqueza del reino, sus dos grandes objetivos imposibles de disociar. Aunque parecería condensar la voz del espacio local y de una vuelta al equilibrio anterior al incremento fiscal, especialmente en lo que respecta a la supresión de las contribuciones excepcionales, los servicios y los millones, lo cierto es que concibió una relación armónica en la que la riqueza de los súbditos se convirtiera en la plataforma del poder del monarca y la acción de este en el elemento esencial del desarrollo de aquellos.

Los plantes de Gaytán referidos a Murcia y Venezuela, así como su propuesta para la modificación del valor de la moneda, apuntaban a favorecer la regeneración del reino según un concepto de riqueza que descansaba en el incremento de la población y en la producción de frutos y manufacturas, metas que perseguían el objetivo de detener el flujo de la plata americana hacia el extranjero. Según concluía de manera muy gráfica, de adoptarse las reformas propuestas

se despoblarán todos los reinos extraños y se repoblarán los de España, pues el temple y fertilidad de sus campos y abundancia de plata y oro asegura su población y aumento [porque] la riqueza y aumento de los reinos consiste en mucha población, vecindad y agricultura, de que se fomenta el trato y comercio y manufactura de lo mecánico y en todo en España por la capacidad que tiene se verá conseguida la proposición [...] pues con el ejemplo claro vemos que por el comercio y manufacturas se ven muy poderosas muchas ciudades y muy ricas provincias que no tienen el sue- 


\begin{abstract}
lo, temple y géneros de España con solo conducir estos reinos a estas provincias y ciudades los frutos de España, con obrarlos en ellas con muy poderosos sin tener donde consumirlos sino volviéndolos a España obrados y utilizados en sus especies con las cuales comen y se sustentan y nos llevan el dinero y pues en estos reinos tenemos los mejores géneros del mundo y quitados los muchos pechos y gabelas que se pagan y las calumnias que por cobrarlos hacen a los vecinos, vendrán a España a millares cada día oficiales con muy poca diligencia que se haga en estos reinos con ofertas y concesiones de algunas preminencias a los oficiales que vinieren a obrar los géneros de este reino se sacan y se venderán muy baratos los tejidos que se obraren para lo cual SM debe mandar prohibir la entrada de las mercaderías que vienen obradas. ${ }^{94}$
\end{abstract}

La visión que ofrecía del mundo hispánico en clave sistémica estaba informada por un pensamiento mercantilista con el que buscaba propiciar la interdependencia entre las distintas regiones de la monarquía, para de este modo establecer sólidas fuentes de riqueza mediante la disposición de las condiciones necesarias para el desarrollo de la industria, la preservación de los mercados internos de las manufacturas importadas, el incremento de los intercambios y, finalmente, la generación de importantes ingresos fiscales que permitieran financiar una política exterior de poder, incluyendo un sistema defensivo acorde a los desafíos extranjeros.

Mediante la acción conjunta del príncipe, de los vasallos y de la administración reformada que el arbitrismo posibilista de Gaytán procuraba encauzar, aún sería posible revertir la decadencia del cuerpo político y volver a recuperar la supremacía que sus enemigos le estaban disputando. De este modo, sus arbitrios traducen una perspectiva optimista respecto del futuro - dependiente de que se adoptaran las decisiones correctas- que se apoyaba en una lectura providencialista — pero no mecanicista— que reconocía que la intervención divina había dispuesto unas condiciones muy propicias para el desenvolvimiento de la monarquía, cuyo aprovechamiento dependía del príncipe, del valido y de sus vasallos.

La mayor parte de las ideas de Gaytán están lejos de ser una creación, sino que retoman tópicos centrales del pensamiento arbitrista e incluso del reformismo desarrollado en el ámbito de la administración. Podríamos referirnos, por ejemplo, al memorial que Pedro Hurtado de Alcocer dirigió a Felipe IV en 1621, a los planes de Abarca, a las propuestas del consejo de Jerez, a las ideas y arbitrios manejados en la Junta de Reformación y en el Consejo de Castilla, a la Restauración política de Moncada y a la Conservación de Monarquías de Fernández de Navarrete, a los Artículos de

94 Gaytán, 1625a, 159-160. 
reformación $\mathrm{o}$, incluso, al propio régimen de Olivares, cuyo planteamiento también era de carácter mercantilista - como lo atestiguan los Capítulos de reformación de 1623 - y contenía varias de las opciones sugeridas por Gaytán que, al menos en los primeros años, se intentaron ejecutar. ${ }^{95}$

Sin embargo, la originalidad del principal aporte de este autor jerezano y el valor de su obra radican, además de en sus propuestas para el desarrollo de Venezuela, en su habilidad para sintetizar ideas que formaban parte de un campo intelectual muy rico y conjugarlas con su experiencia colonial para dar lugar a un arbitrismo concebido, precisamente, a escala del mundo hispánico en el que se contemplaba, incluso, la función del Extremo Oriente. De este modo, sus memoriales nos permiten apreciar la construcción intelectual de la monarquía policéntrica desde la óptica de unos arbitrios en los que los virreinatos americanos se relacionaban de forma espontánea con el mundo europeo, reproduciendo - no conviene olvidarlo- las percepciones contemporáneas acerca de las dificultades y de las soluciones para los disfuncionamientos de la extensa monarquía de los Austrias.

Recibido el 10 de enero de 2014 Aceptado el 6 de abril de 2014

\section{Bibliografía}

Abellán, José Luis: Historia crítica del pensamiento español, tomo 3, Madrid, Espasa Calpe, 1981.

Amadori, Arrigo: «Que se dé diferente modo al gobierno de las Indias, que se van perdiendo muy a prisa. Arbitrismo y administración a principios del siglo XVII», Anuario de Estudios Americanos, 66-2, Sevilla, 2009, 147-179.

Amadori, Arrigo: Negociando la obediencia. Gestión y reforma de los virreinatos americanos en tiempos del conde-duque de Olivares, Madrid, CSIC, EEHA, Junta de Andalucía, 2013.

Burgos Esteban, Francisco Marcos: «Dificultades en la práctica de gobernar. El riego de Lorca, Murcia y Cartagena (1617-1622)», Cuadernos de Historia Moderna, 16, Madrid, 1995, 80-101.

95 Moncada, 1974; Fernández de Navarrete, 1626; Consulta del Consejo Real a Felipe III, Madrid, 1 de noviembre de 1619; Memorial de Pedro Hurtado de Alcocer a Felipe IV, Madrid, 9 de diciembre de 1621; Capítulos de Reformación que SM se sirve de mandar guardar por esta ley para el gobierno de reino, Madrid, 11 de febrero de 1623, todos en González Palencia, 1932, 12 y ss., 164 y ss., y 417 y ss.; Elliott, 2004, 177. 
Castillo de Bobadilla, Jerónimo: Política para corregidores y señores de vasallos..., Madrid, Luis Sánchez, 1597.

Chacón Jiménez, Francisco (dir.): Historia de la región murciana, VI, Murcia, Mediterráneo, 1980.

Clavero, Bartolomé: «La Monarquía, el Derecho y la Justicia», en Martínez Ruiz, Enrique y Pazzis Pi Corrales, Magdalena (coords.), Instituciones de la Edad Moderna. I. Las Jurisdicciones, Madrid, Editorial Atlas, 1996, 15-38.

Díaz Blanco, José Manuel: «El comercio de El Puerto de Santa María en la década de 1630: ¿una coyuntura crítica?», Revista de Historia de El Puerto, 43, 2009, 69-86.

Díaz Blanco, José Manuel: «Presión monárquica y resistencia municipal: Jerez de la Frontera contra el gobierno de Felipe IV», Studia Histórica. Historia Moderna, 34, Salamanca, 2012, 283-304.

Elliott, John: «América y el problema de la decadencia española», Anuario de Estudios Americanos, XXVIII, Sevilla, 1971, 1-23.

Elliott, John: El conde-duque de Olivares y la herencia de Felipe II, Valladolid, Universidad de Valladolid, 1977.

Elliott, John: «Introspección colectiva y decadencia en España a principios del siglo XVII», en Elliott, John (ed.), Poder y sociedad en la España de los Austrias, Madrid, Crítica, 1982, 198-223.

Elliott, John: El conde-duque de Olivares. El político en una época de decadencia, Barcelona, Crítica, 2004 [1986].

Fernández de Navarrete, Pedro: Conservación de monarquías y discursos que políticos sobre la consulta que el Consejo hizo al rey don Felipe tercero, Madrid, Imprenta Real, 1626.

Fernández-Santamaría, José: Razón de Estado y política en el pensamiento del barroco (1595-1640), Madrid, Centro de Estudios Políticos y Constitucionales, 1986.

García García, Bernardo José: La Pax Hispanica. Política exterior del duque de Lerma, Lovaina, Leuven University Press, 1996.

García Guerra, Elena: Moneda y arbitrios: consideraciones del siglo XVII, Madrid, CSIC, 2003.

Gaytán de Torres, Manuel: «Memorial sobre la propuesta del capitán Carmona», s.1., s.f., Biblioteca Nacional, Madrid, mss. 1092, 395r-398v.

Gaytán de Torres, Manuel: Relación y vista de oios que Don Manuel Gaytan de Torres Veintiquatro de la ciudad de Xerez, haze a su Magestad en el Real Consejo de las Indias, por comission que para ello tuvo de las Minas de cobre que hay en las Serranias de Cocorote, provincia de Venezuela. Año 1621, edición facsimilar de Antonio Moreno Garrido, Almería, Granada, 1968.

Gaytán de Torres, Manuel: Reglas para el gouierno destos Reynos de los de las Indias, con aumento de su población y en la Real Hacienda, y armas de la 
mar dirigidas al Excelentissimo Señor Conde Duque, s.1., 1625(a), Biblioteca Nacional, Madrid, mss 3/3532.

Gaytán de Torres, Manuel: Discursos que disponen medios para la restauración de España con mayor cantidad de renta en la Real Hacienda, y menos gabelas en estos reynos, y aumento de su población, y en las fuerzas de mar, s.l., 1625(b), Biblioteca del Palacio Real, Madrid, mss. II/1452.

Gelabert, Juan: La bolsa del rey, Barcelona, Crítica, 1991.

Gelabert, Juan: Castila convulsa (1631-1652), Madrid, Marcial Pons, 2001.

Gil Pujol, Xavier: «La Razón de Estado en la España de la Contrarreforma», en

Rus, Rufino, et al., La Razón de Estado en la España Moderna, Valencia, Sociedad Económica de Amigos del País, 2000, 355-374.

González Palencia, Ángel: La Junta de la Reformación, Valladolid, Poncelix, 1932.

Hespanha, Antonio Manuel: Vísperas del Leviatán. Instituciones y poder político (Portugal, siglo XVII), Madrid, Taurus, 1989.

Israel, Jonathan: La República Holandesa y el mundo hispánico, 1606-1661, Madrid. Nerea, 1997.

Lucena Salmoral, Manuel: Piratas, bucaneros, filibusteros y corsarios en América, Madrid, MAPFRE, 1992.

Marañón, Gregorio: El conde-duque de Olivares. La pasión de mandar, Madrid, Espasa Calpe, 2006 [1933].

Maravall, José Antonio: Estudios de Historia del Pensamiento Español, III, Madrid, Taurus, 1986.

Moncada, Sancho: Restauración política de España, [1619], ed. De Jean Vilar, Madrid, Instituto de Estudios Fiscales, 1974.

Pérez Escolano, Víctor: «El Guadalquivir, vía de comunicación privilegiada. El frustrado proyecto de nueva canalización de 1624», en Los caminos y el arte: VI Congreso Español de Historia del Arte, II, Santiago, Universidad de Santiago de Compostela, 1989, 33-43.

Postigo Castellanos, Elena: Honor y privilegio en la Corona de Castilla. El Consejo de las Órdenes y los Caballeros de Hábito en el siglo XVII, Soria, Junta de Castilla y León, 1988.

Ruiz Ibáñez, José Javier: Las dos caras de Jano: monarquía, ciudad e individuo: Murcia, 1588-1648, Murcia, Servicio de Publicaciones Universidad de Murcia, 1995.

Ruiz Rodríguez, José Ignacio: Las Órdenes Militares en la Edad Moderna, Madrid, Arco, 2001.

Santa María, Juan de: Republica y policia christiana para reyes y principes y para los que en el govierno tienen sus vezes, Barcelona, Casa de Lorenzo Deu, 1619.

Sancho de Sopranis, Hipólito: Historia de Jerez de la Frontera desde su incorporación a los dominios cristianos, 3, Jerez, Jerez Industrial, 1969. 


\section{REMEDIOS PARA UN CUERPO POLÍTICO QUE DECLINA}

Serrano Mangas, Fernando: Armadas y flotas de la plata (1620-1648), Madrid, Banco de España, 1989.

Spínola y Torres, Juan: Descripción de las fiestas de cañas y toros celebradas en Jerez de la frontera el año 1630 con motivo del nacimiento del príncipe D. Baltasar Carlos, edición y notas de Juan Moreno de Guerra y Alonso, Madrid, Sucesores de Rivadeneyra, 1916.

Urbani, Franco: «Las minas de cobre de Aroa a la luz de la relación de Manuel Gaytán de Torres, 1621», Boletín Geológico y Minero, 103-2, Madrid, 1992, 156-185.

Verna, Paul: «Minas de Aroa», en Diccionario de Historia de Venezuela, I, Caracas, Fundación Polar, 1988, 191-192.

Vilar Berrogaín, Jean: «Una pauta del pensamiento monetarista castellano: la Proposición Cardona», en Dinero y crédito, (siglos XVI al XIX): actas del primer Coloquio Internacional de Historia Económica, Madrid, 1978, 449-457.

Vila Vilar, Enriqueta: Historia de Puerto Rico, Sevilla, EEHA, 1974.

Viroli, Mauricio: De la política a la razón de Estado. La adquisición y transformación del lenguaje político moderno (1250-1600), Madrid, Akal, 2009. 